\title{
Gim Edukasi Bernarasi Cerita untuk Edukasi Prasekolah Normal Baru: Studi Kasus di TK Lintang, Surabaya
}

\author{
Pratama Wirya Atmaja ${ }^{1 *}$, Sugiarto ${ }^{2}$, dan Diana Aqidatun Nisa ${ }^{3}$ \\ 1,2)Program Studi Informatika, Fakultas Ilmu Komputer \\ 3)Program Studi Desain Komunikasi Visual, Fakultas Arsitektur dan Desain \\ Universitas Pembangunan Nasional "Veteran" Jawa Timur \\ Jl. Raya Rungkut Madya, Gunung Anyar, Surabaya, 60294 \\ *email:pratama_wirya.fik@upnjatim.ac.id
}

(Naskah masuk: 25 Desember 2020; diterima untuk diterbitkan: 26 April 2022)

\begin{abstract}
ABSTRAK - Gim edukasi adalah metode mutakhir untuk edukasi di abad ke-21. Walau demikian, gim edukasi belum diterapkan untuk edukasi normal baru di prasekolah. Untuk memberi sumbangsih terkait topik tersebut, kami mengembangkan sebuah gim edukasi untuk membantu TK Lintang, sebuah lembaga prasekolah di Surabaya, melaksanakan pengajaran "Jari Aritmetika". Kami memilih novel visual sebagai jenis permainan gimnya, dan gim tersebut menyajikan Jari Aritmetika yang dibungkus narasi cerita dan tampilan kartun. Kami mengembangkan gim tersebut dalam dua iterasi dengan mempertimbangkan "kemudahan penggunaan" sebagai kebutuhan nonfungsionalnya. Hasil-hasil kami adalah dua versi gimnya (mobile dan desktop) dan sebuah sistem informasi untuk memodifikasi soal-soal aritmetika di gimnya. Dalam proses pengujian yang diikuti empat siswa dan orangtua masing-masing, gim kami mendapatkan nilai rata-rata 4,79 dari maksimal 5, yang menandakan efektivitasnya untuk hiburan dan edukasi. Kami telah pula mengekstrak lima prinsip penerapan gim edukasi untuk pendidikan prasekolah normal baru. yang salah satunya adalah memfasilitasi "waktu keluarga" di antara siswa dan orangtuanya.
\end{abstract}

Kata Kunci - Gim edukasi; normal baru; prasekolah; novel visual; aritmetika.

\section{Narrative Educational Games for New-Normal Preschool Education: A Case Study in TK Lintang, Surabaya}

\begin{abstract}
Educational games are a state-of-the-art method for education in the 21st century. However, they have not been applied for new-normal education in preschools. To contribute to the matter, we developed an educational game to help TK Lintang, a preschool institution in Surabaya, conduct "Jari Aritmetika" or "Magic Fingers" learning and teaching. We chose the visual novel as the game's genre, and the game presented Jari Aritmetika through storytelling and cartoon visuals. We developed the game in two iterations by considering "ease of use" as its nonfunctional requirement. Our results are two versions of the game (mobile and desktop) and an information system for modifying the game's arithmetic questions. Our game acquired a 4.79, out of 5, mean value in a testing process involving four students and their parents, proving the game's effectiveness for entertainment and education. We have also extracted five principles of educational game applications in new-normal preschool education, including facilitating "family time" between students and their parents.
\end{abstract}

Keywords - Educational games; new normal; preschools; visual novel; arithmetic.

\section{Pendahuluan}

Pandemi COVID-19 memaksa pembelajaran di sekolah dan penerapan pembelajaran di rumah [1]. Senjata utama para pendidik untuk mensiasati hal itu adalah pembelajaran daring melalui teknologi informasi dan komunikasi (TIK)[2]. Berbagai penelitian telah dilakukan terkait pendidikan daring di masa normal baru, mulai dari tingkat prasekolah [3] dan sekolah dasar [4] hingga pendidikan tinggi [5]. Menurut Kim [3], permainan dan aktivitas-aktivitas langsung 
(hands-on activities) berperan penting di prasekolah, tetapi dua hal tersebut sukar dilakukan secara daring. Gim edukasi memiliki potensi untuk menjadi solusi masalah tersebut, terutama karena gim semakin digemari di masa pandemi [6]. Walau demikian, penerapan gim edukasi untuk pendidikan normal baru di prasekolah masih luput dari perhatian. Untuk memberi sumbangsih terkait topik tersebut, maka dibuatlah pengembangan gim edukasi di Taman Kanak-Kanak (TK) Lintang Surabaya.

\subsection{Perkembangan Keilmuan Terkini}

Bidang pendidikan terus berkembang, terutama dengan memanfaatkan kekuatan TIK [7]. Salah satu jenis TIK termutakhir untuk pendidikan adalah gim edukasi, yang dikenal pula dengan istilah pembelajaran berbasis gim (game-based learning) [8]. Pasar gim edukasi di seluruh dunia terus meningkat dengan pesat [9]; berbagai manfaat gim edukasi pun telah diteliti dan diakui, seperti membangkitkan emosi-emosi positif dan motivasi belajar [10], meningkatkan otonomi dan kompetensi siswa [11], dan menimbulkan pengalaman Flow [12]. Indonesia pun tidak hendak tertinggal dalam penggunaan gim edukasi, sebagaimana yang ditunjukkan Atmaja dkk. [13] dan Syahidi [14].

Salah satu pasar potensial untuk gim edukasi adalah institusi pendidikan prasekolah [15]. Zanchi dkk. [16] melakukan penelitian skala besar terhadap 50 purwarupa aplikasi gim matematika prasekolah, yang pada akhirnya menghasilkan delapan aplikasi. Papanastasiou dkk. [17] meneliti penerapan gim edukasi di taman kanak-kanak dan sekolah dasar dan menemukan efek positifnya terhadap kurikulum sekolah.

Terkait pembelajaran matematika bagi anak prasekolah, satu metode yang efektif adalah Jari Aritmetika atau Magic Finger Teaching Method (MFTM) [18]. Martono dkk. [19] dan Ahmadi dan Weijun [20] mengembangkan aplikasi gim dan multimedia untuk pembelajaran Jari Aritmetika di sekolah dasar. Baik Martono dkk. maupun Ahmadi dan Weijun menggunakan pendekatan visual dengan menampilkan gambar-gambar tangan dan jari-jemari kartun di layar, sehingga pemain dapat mengingat dan langsung menirukan teknik Jari Aritmetika yang ditampilkan. Ahmadi dan Weijun mengamati peningkatan signifikan kemampuan berhitung para siswa yang memainkan aplikasi mereka.

Salah satu aspek penting gim adalah narasi cerita. Efektivitas gim edukasi pun dapat meningkat jika jalan permainan dan materi pembelajarannya dibungkus narasi cerita [21]. Narasi cerita digital memang telah diterapkan di bidang edukasi untuk berbagai manfaat seperti meningkatkan memori visual dan kemampuan menulis [22].

\subsection{Kontribusi Ilmiah}

Penelitian ini memberikan dua kontribusi ilmiah. Pertama, kami melakukan studi kasus pembuatan gim edukasi, yang dapat menjadi studi awal (preliminary study) penerapan gim edukasi untuk prasekolah di era normal baru. Kedua, kami mengumpulkan lima prinsip atau best practices yang dapat mendukung penerapan tersebut.

\section{Metode Penelitian}

\subsection{Deskripsi Studi Kasus}

Yayasan Lintang Fajar adalah lembaga di Surabaya yang bergerak di bidang pendidikan melalui TK Lintang. Terkait dengan pembelajaran berhitung, TK Lintang menerapkan metode Jari Aritmetika untuk membantu prosesnya. Walau Jari Aritmetika memiliki prinsip yang sederhana, penerapannya di depan siswa membutuhkan keahlian dan kesabaran agar siswa dapat memahami dan menirukannya. Hal tersebut tersebut menjadi kendala di tengah wabah COVID-19, di mana pembelajaran di sekolah dibatasi dan pembelajaran di rumah diterapkan. Karena faktor keahlian dan kesabaran yang dibutuhkan, pihak orangtua pun kesulitan mempelajarinya dan menerapkannya pada anak-anak mereka di rumah.

Sebagai solusi atas permasalahan tersebut, kami mengembangkan sebuah gim edukasi untuk mendukung pengajaran Jari Aritmetika di TK Lintang. Gim berjudul "Petualangan Jari Aritmatika" (disingkat sebagai PJA) tersebut mendukung pembelajaran normal baru yang fleksibel: di rumah, di sekolah, maupun secara daring.

\subsection{Alur Pengembangan Gim}

Gambar 1 menunjukkan alur pengembangan PJA yang melibatkan tiga pihak: tim kami, para guru TK Lintang, dan para siswa dan orangtua. Pengembangan menggunakan metodologi iteratif yang telah sangat umum digunakan untuk pengembangan gim [23]. Alur pengembangan dimulai dengan rekayasa kebutuhan (requirement engineering) PJA, yang dilakukan dengan kunjungan ke TK Lintang untuk melakukan survei dan diskusi dengan para guru. Setelah kebutuhan PJA didapatkan, proses pengembangan dilakukan dalam sejumlah iterasi yang masing-masing berlangsung selama beberapa minggu. Setiap iterasi akan menghasilkan sebuah versi PJA yang dapat dimainkan, yang akan diujikan di TK Lintang. Jika hasil pengujian mengindikasikan perlunya perbaikan pada PJA, perbaikan tersebut akan 
dilakukan pada desain dan perangkat lunak PJA. Jika hasil pengujian tidak menunjukkan kekurangan PJA, proses dapat dilanjutkan ke tahap finalisasi untuk menghasilkan perangkat lunak PJA yang siap diterapkan di TK Lintang.

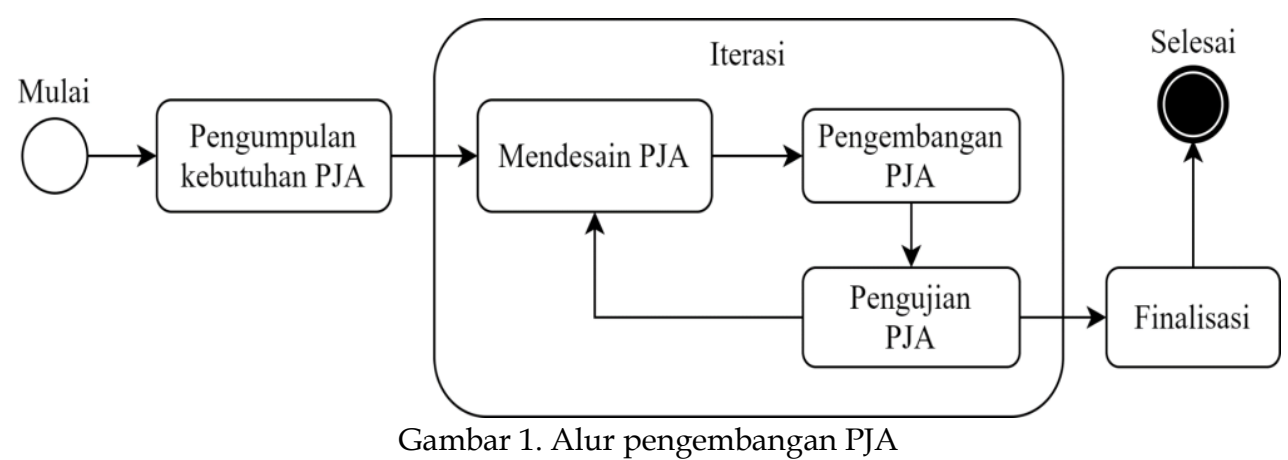

\subsection{Kebutuhan Perangkat Lunak Gim}

Kunjungan pertama kami pada TK Lintang mengungkap dua hal yang terkait dengan kebutuhan perangkat lunak PJA: (1) rencana skenario penggunaan PJA di TK Lintang, dan (2) bagaimana pandangan para guru TK Lintang terhadap penggunaan gim dan TIK untuk proses belajarmengajar. Berdasarkan skenario penggunaan PJA, sejumlah kebutuhan fungsional PJA adalah:

1. PJA menampilkan soal-soal aritmetika yang dibungkus alur cerita untuk menarik para siswa;

2. PJA harus menampilkan soal-soal aritmetika yang melibatkan objek-objek di alur ceritanya, dan gambar objek-objek itu harus ditampilkan di tampilan soalnya;

3. Agar sesuai dengan tingkat kemampuan para siswa, soal-soal aritmetika di PJA adalah terkait penjumlahan dua angka yang masing-masing tidak lebih besar dari sepuluh;

4. PJA harus diciptakan untuk komputer desktop, yang akan digunakan di TK Lintang, dan perangkat mobile, yang akan digunakan para siswa di rumah;

5. Soal-soal aritmetika di PJA harus dapat dimodifikasi para guru, sehingga PJA dapat digunakan untuk jangka panjang;

6. PJA harus dapat menampilkan data prestasi pemain di akhir sesi permainan; dan

7. PJA harus menampilkan animasi tangan peraga Jari Aritmetika di tampilan soal.

Untuk mengungkap hal kedua, kami meminta para guru mengisi kuesioner yang didasarkan pada Technology Acceptance Model [24]. Hasil kuesioner tersebut mencerminkan antusiasme yang diiringi kecemasan; para guru merasa tertarik menggunakan PJA dan sekaligus tidak yakin apakah mereka sanggup melakukan itu. Berdasarkan pandangan para guru tersebut, kami menetapkan "kemudahan penggunaan" sebagai kebutuhan non-fungsional PJA. Lebih jelasnya, PJA harus mudah digunakan anak-anak dan orang yang awam terhadap TIK.
Selain itu, fitur modifikasi terhadap soal-soal di PJA juga harus mudah digunakan orang awam.

\subsection{Desain Sistem Gim}

Sistem gim edukasi kami terdiri dari dua aplikasi, yaitu PJA dan Sistem Informasi Manajemen Gim Jari Aritmatika (disingkat sebagai SIMGEJA). Gambar 2 memperlihatkan rancangan sistem kami. Terdapat dua jenis pengguna sistem tersebut, yaitu Siswa dan Guru. Siswa menggunakan PJA, yang berjenis novel visual [25], untuk mempelajari Jari Aritmetika, sedangkan Guru menggunakan SIMGEJA, yang berbasis web, untuk memodifikasi konten pembelajaran Jari Aritmetika di PJA. Dengan demikian, PJA dapat digunakan untuk jangka panjang di TK Lintang. Pengembangan PJA dilakukan menggunakan GameMaker Studio 2, yang mendukung pengembangan gim dua dimensi dan multiplatform.

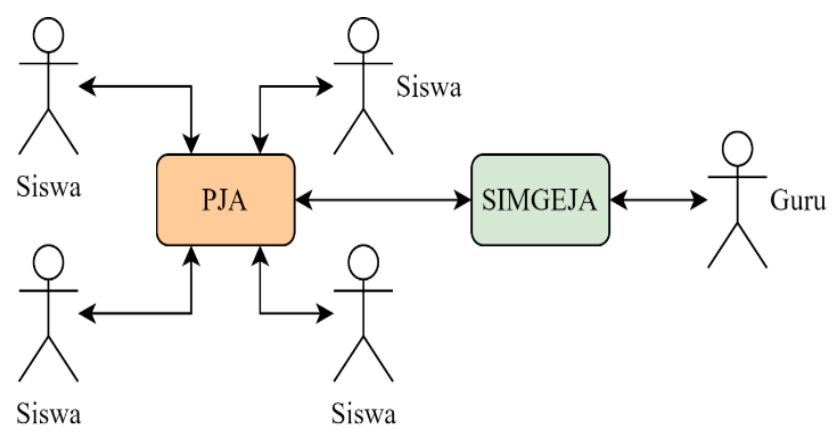

Gambar 2. Sistem gim Jari Aritmetika yang melibatkan PJA dan SIMGEJA

\subsection{Desain Alur Permainan Gim}

Sebagai novel visual, PJA menyampaikan pembelajaran Jari Aritmetika yang dibungkus narasi cerita. Berdasarkan taksonomi Camingue dkk. [25], PJA menerapkan strategi "pengajaran melalui gim mini" (teaching through mini-games). Untuk itu, kami mendesain alur permainan PJA agar tersusun dari dua bagian, yaitu adegan cerita dan soal. Soal-soal 
aritmetika yang ditampilkan berfungsi sebagai "gim mini" yang berada di dalam PJA sebagai "gim besar"-nya.

Gambar 3 memperlihatkan desain tampilan soal. Teks soal aritmetika ditampilkan di tengah layar, diiringi empat tombol jawaban di bawahnya. Dua unsur di kanan dan kiri teks soal adalah animasi tangan yang memeragakan Jari Aritmetika, yang akan otomatis disesuaikan dengan angka jawaban yang benar. Animasi tersebut memandu siswa untuk mempraktekkan Jari Aritmetika.

Teks soal akan menyebutkan nama dua jenis objek yang menjadi sasaran operasi aritmetikanya; sebagai contoh, "Berapa hasil penjumlahan lima gajah dan tujuh monyet?" Gambar dua jenis objek tersebut ditampilkan di bawah animasi kedua tangan.

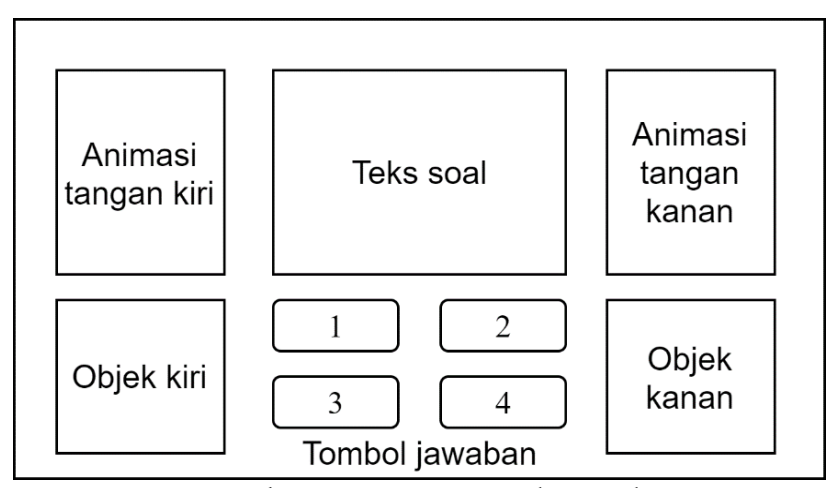

Gambar 3. Desain tampilan soal

\subsection{Desain Alur Cerita Gim}

Pada penelitian ini didesain sebuah alur cerita yang menarik, mudah dipahami, dan sekaligus mengandung muatan moral kekinian. Tokoh utama adalah seorang anak kecil yang penasaran dengan pandemi COVID-19. Ketika hendak tidur di suatu malam, anak berdoa pada Tuhan agar membantu orang-orang yang terkena dampak pandemi. Tibatiba seorang ibu peri muncul dan menawarkan anak untuk ikut dengannya. Anak menerima, lalu keduanya terbang berkeliling kota untuk menemukan dan membantu korban-korban pandemi.

Pada penelitian ini dilakukan penyeragaman pola kemunculan soal-soal di PJA. Sebelum tokoh utama dapat membantu seorang korban pandemi, pemain harus menjawab sebuah soal yang terkait dengan sang korban. Sebagai contoh, sebelum membantu seorang penjual bakso, pemain harus menjawab soal "Berapakah jumlah total mangkuk jika terdapat lima mangkuk bakso dan tujuh mangkuk gorengan?" Terlepas dari benar-salahnya jawaban pemain, alur cerita akan dilanjutkan setelahnya dengan keberhasilan tokoh utama menolong sang korban.

\subsection{Pengujian Gim}

Pengujian PJA dilakukan di TK Lintang dengan partisipasi para guru, murid, dan orangtua murid. Kami menggunakan metode campuran (mixedmethod) yang terdiri dari pengamatan, diskusi, dan kuesioner. Pengamatan dan diskusi menghasilkan data kualitatif, sedangkan kuesioner menghasilkan data kuantitatif.

Karena para guru dan para murid menggunakan PJA untuk tujuan yang berbeda, kami menggunakan dua kuesioner. Kedua kuesioner dinilai dengan skala Likert lima nilai. Untuk para guru, kami mendesain kuesioner yang terdiri dari delapan kriteria penilaian, yang juga didasarkan pada Technology Acceptance Model [24]:

1. Anda merasa bahwa mempelajari cara menggunakan PJA adalah mudah;

2. Anda merasa bahwa PJA dapat meningkatkan kinerja Anda dalam mengajar;

3. Anda merasa bahwa PJA menyenangkan untuk dipelajari dan digunakan;

4. Anda merasa antusias dalam menggunakan PJA untuk membantu Anda mengajar;

5. Anda merasa dapat terbiasa menggunakan PJA dalam proses belajar-mengajar sehari-hari;

6. Anda merasa lingkungan di sekitar Anda mendukung Anda menggunakan PJA;

7. Anda yakin mampu menggunakan PJA untuk mengajar;

8. Anda merasa penggunaan PJA sesuai visi dan misi pendidikan lembaga dan pemerintah.

Tabel 1 memperlihatkan kuesioner untuk para siswa. Kuesioner tersebut diisi oleh orangtua siswa berdasarkan pengamatan mereka terhadap si siswa ketika memainkan PJA. Kuesioner tersebut didasarkan pada Game User Experience Satisfaction Scale [26] dan model EGameFlow [27].

\section{HASIL DAN PEMbahasAN}

\subsection{Hasil Pengembangan Iterasi Pertama}

Pada iterasi pertama pengembangan PJA, kami mendesain dan mengembangkan PJA sesuai kebutuhan awalnya. PJA versi pertama tersebut adalah untuk komputer desktop bersistem operasi Windows. Kami menggunakan aset-aset grafis seadanya, sebagaimana tampak di Gambar 4. PJA iterasi pertama tersebut kemudian dipresentasikan di TK Lintang pada lima orang guru. Hasil kuesioner para guru terkait PJA di pengujian di iterasi pertama dapat dilihat di Tabel 2. Dua pernyataan bernilai tertinggi ditandai warna hijau muda, sementara pernyataan bernilai terendah ditandai warna jingga.

Secara keseluruhan, PJA versi pertama tersebut tidak terlalu diterima para guru. Pernyataan kedua ("Anda merasa bahwa PJA dapat meningkatkan kinerja Anda dalam mengajar") dan keenam ("Anda merasa lingkungan di sekitar Anda mendukung 
Anda menggunakan PJA") mendapat nilai tertinggi, yang menunjukkan pandangan positif para guru terkait penggunaan PJA. Terlepas dari hal itu, para guru juga merasa pesimis akan keberhasilan dan kelancaran mereka dalam menggunakan PJA secara riil, yang tercermin dari nilai pernyataan pertama ("Anda merasa bahwa mempelajari cara menggunakan PJA adalah mudah") dan ketujuh ("Anda yakin mampu menggunakan PJA untuk mengajar").

Tabel 1. Kuesioner pengujian PJA oleh siswa TK Lintang

\begin{tabular}{|c|c|c|}
\hline Bagian & No. & Pernyataan \\
\hline \multirow[t]{5}{*}{$\begin{array}{l}\text { Jalan per- } \\
\text { mainan }\end{array}$} & 1 & $\begin{array}{l}\text { Jalan permainan terasa } \\
\text { menyenangkan. }\end{array}$ \\
\hline & 2 & $\begin{array}{l}\text { Saya ingin memainkan } \\
\text { ulang gimnya untuk } \\
\text { merasakan kesenangan } \\
\text { memainkannya lagi. }\end{array}$ \\
\hline & 3 & $\begin{array}{l}\text { Cara memainkan gimnya } \\
\text { mudah dipahami. }\end{array}$ \\
\hline & 4 & $\begin{array}{l}\text { Antarmuka gimnya mudah } \\
\text { digunakan. }\end{array}$ \\
\hline & 5 & $\begin{array}{l}\text { Informasi terkait jalan } \\
\text { permainan disajikan dengan } \\
\text { jelas di dalam gimnya. }\end{array}$ \\
\hline \multirow[t]{4}{*}{$\begin{array}{l}\text { Unsur } \\
\text { edukasi }\end{array}$} & 6 & $\begin{array}{l}\text { Jalan permainan menambah } \\
\text { pengetahuan seputar Jari } \\
\text { Aritmatika. }\end{array}$ \\
\hline & 7 & $\begin{array}{l}\text { Saya termotivasi untuk } \\
\text { menerapkan Jari Aritmatika } \\
\text { selama memainkan gimnya. }\end{array}$ \\
\hline & 8 & $\begin{array}{l}\text { Saya termotivasi untuk } \\
\text { menerapkan Jari Aritmatika } \\
\text { di kehidupan sehari-hari. }\end{array}$ \\
\hline & 9 & $\begin{array}{l}\text { Saya merasa ingin } \\
\text { mengetahui lebih lanjut } \\
\text { seputar Jari Aritmatika. }\end{array}$ \\
\hline \multirow[t]{4}{*}{$\begin{array}{l}\text { Audio- } \\
\text { visual }\end{array}$} & 10 & $\begin{array}{l}\text { Saya menikmati musik dan } \\
\text { efek suara di permainannya. }\end{array}$ \\
\hline & 11 & $\begin{array}{l}\text { Musik dan efek suara di } \\
\text { gimnya sesuai dengan tema } \\
\text { permainannya. }\end{array}$ \\
\hline & 12 & $\begin{array}{l}\text { Grafik gimnya sesuai } \\
\text { dengan tema permainannya. }\end{array}$ \\
\hline & 13 & $\begin{array}{l}\text { Grafik gimnya menarik } \\
\text { untuk dilihat. }\end{array}$ \\
\hline \multirow[t]{4}{*}{$\begin{array}{l}\text { Jalan } \\
\text { cerita }\end{array}$} & 14 & $\begin{array}{l}\text { Saya tertarik mengikuti jalan } \\
\text { cerita gimnya sejak awal. }\end{array}$ \\
\hline & 15 & $\begin{array}{l}\text { Saya menikmati unsur } \\
\text { fantasi yang disajikan } \\
\text { gimnya. }\end{array}$ \\
\hline & 16 & $\begin{array}{l}\text { Saya merasa menjadi } \\
\text { karakter utama di gimnya. }\end{array}$ \\
\hline & 17 & $\begin{array}{l}\text { Saya dapat memahami jalan } \\
\text { cerita gimnya dengan jelas. }\end{array}$ \\
\hline
\end{tabular}

Berdasarkan diskusi dengan para guru, kami membuat beberapa perubahan untuk PJA versi berikutnya:

1. Gambar setiap objek sasaran perhitungan ditampilkan sejumlah objeknya di soalnya, sehingga siswa dapat mengetahui jumlah tersebut secara visual;

2. Keempat tombol jawaban diperbesar agar lebih mudah ditekan;

3. Gaya visual keseluruhan diubah menjadi gaya kartun yang lebih disukai anak-anak.

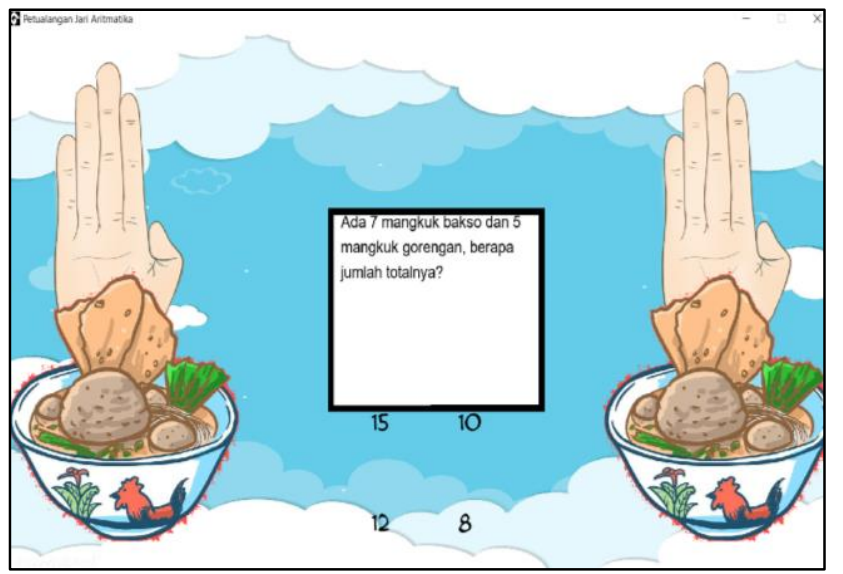

Gambar 4. Tampilan soal di PJA versi pertama dengan aset-aset grafis seadanya

Tabel 2. Hasil kuesioner para guru terkait PJA iterasi pertama

\begin{tabular}{ccc}
\hline No. & Nilai rata-rata & Simpangan baku \\
\hline 1 & 2,80 & 1,10 \\
2 & 3,60 & 0,89 \\
3 & 3,40 & 0,89 \\
4 & 3,20 & 1,10 \\
5 & 3,00 & 1,00 \\
6 & 3,60 & 0,89 \\
7 & 2,60 & 0,89 \\
8 & 3,20 & 1,10 \\
Semua & $\mathbf{3 , 1 8}$ & - \\
kriteria & & \\
\hline
\end{tabular}

\subsection{Hasil Pengembangan Iterasi Kedua}

Gambar 5 memperlihatkan tampilan soal di PJA iterasi kedua, yang merupakan perbaikan dari versi sebelumnya. Di PJA versi kedua tersebut, jumlah gambar-gambar objek sasaran perhitungan telah dapat disesuaikan otomatis dengan angka-angka yang dijumlahkan. Tombol-tombol jawaban juga telah diperbesar agar lebih mudah ditekan. Sementara itu, Gambar 6 memperlihatkan contoh adegan cerita di PJA versi kedua. Gambar-gambar karakter, objek, dan latar belakang telah diubah menjadi bergaya kartun gambaran tangan (handdrawn) agar menyerupai ilustrasi buku cerita anakanak. 
Gambar 7 memperlihatkan layar modifikasi PJA, yang mencakup slider bar untuk mengatur kecepatan animasi tangan. Melalui layar itu, pemain juga dapat mengunduh soal-soal yang telah disusun guru melalui SIMGEJA. Proses penyusunan soal-soal itu akan dijelaskan di bagian terkait SIMGEJA.

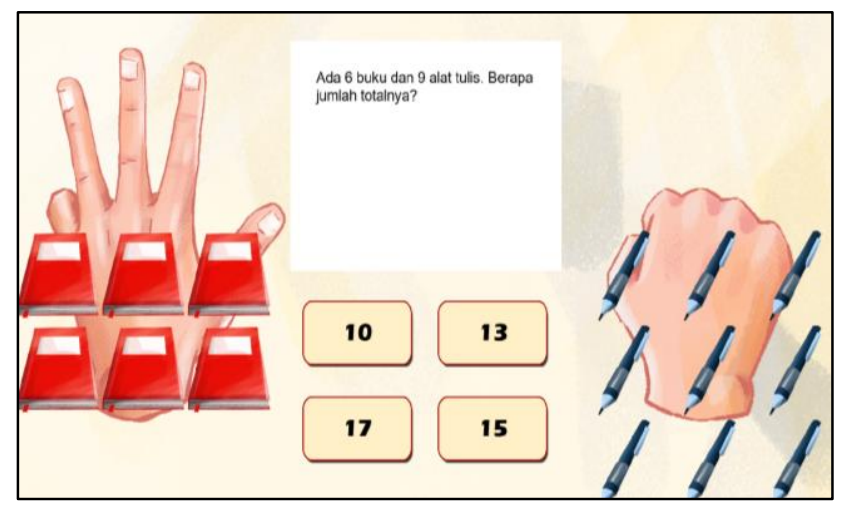

Gambar 5. Tampilan soal di PJA versi kedua dengan asetaset grafis hasil karya tim kami

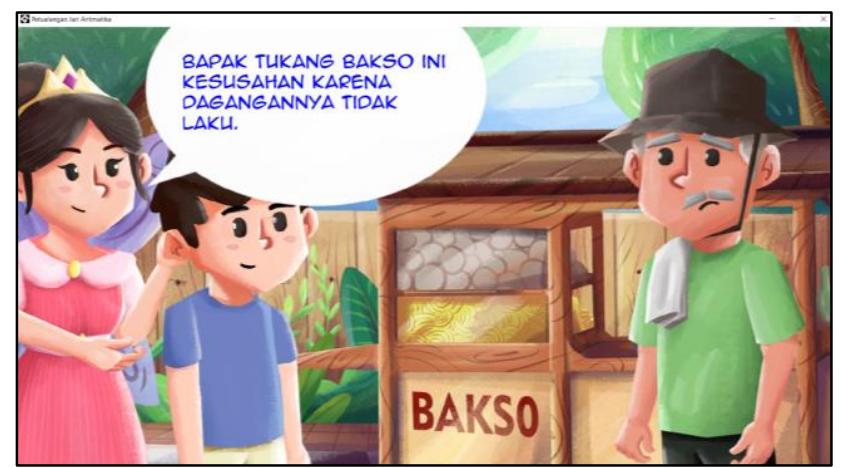

Gambar 6. Tampilan adegan cerita di PJA versi kedua

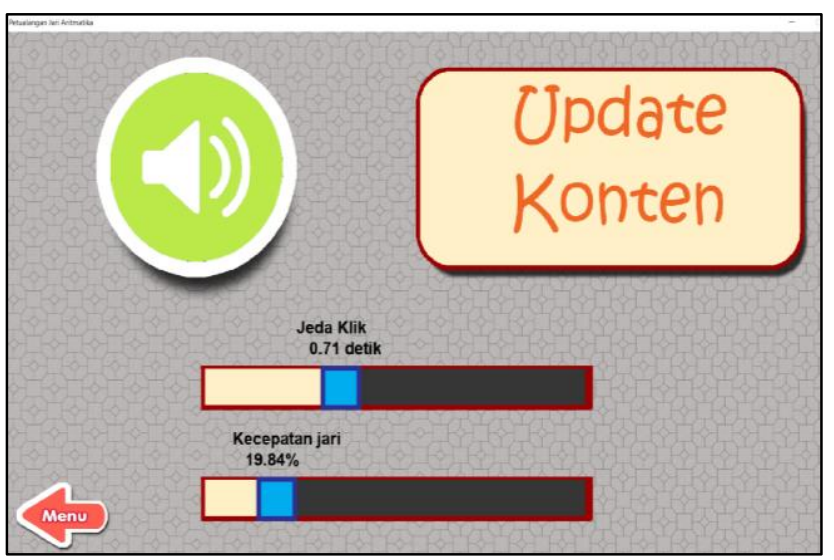

Gambar 7. Layar modifikasi PJA, yang mencakup slider bar untuk kecepatan animasi tangan

Kami tidak dapat mengumpulkan pendapat para guru terkait versi kedua PJA karena hanya satu guru yang mendampingi kami di pengujian di iterasi kedua. Karena tuntutan pembatasan sosial, hanya empat siswa beserta orangtua masing-masing yang berpartisipasi di proses pengujian versi kedua PJA. Secara keseluruhan, para siswa dan orangtua memberi penilaian sangat positif pada PJA.
Sebagaimana terlihat di Tabel 3, hampir seluruh dari 17 pernyataan mendapat nilai rata-rata 4,75 , dan pernyataan 6 hingga 8 (yang berwarna hijau muda) bahkan mendapat nilai sempurna. Nilai rata-rata semua pernyataan adalah 4,79, yang menandakan keberhasilan versi kedua PJA dalam menghibur sekaligus mengedukasi para siswa.

Kami mendukung data kuesioner tersebut dengan data kualitatif dari pengamatan kami dan diskusi dengan para orangtua. Berdasarkan pengamatan kami, para siswa dapat bermain dengan penuh konsentrasi dengan didampingi orangtua masingmasing, yang membacakan teks percakapan dan menuntun si siswa mengerjakan soal-soal. Melalui diskusi, para orangtua juga mengungkapkan betapa memainkan PJA bersama anak-anak mereka terasa menyenangkan. Oleh sebab itu, kami menyimpulkan bahwa PJA dapat mendukung pembelajaran di rumah yang bersifat "waktu keluarga" atau "family time".

Tabel 3. Hasil kuesioner pengujian gim di iterasi kedua

\begin{tabular}{ccc}
\hline \multicolumn{1}{c}{ No. } & Nilai rata-rata & Simpangan baku \\
\hline 1 & 4,75 & 0,5 \\
2 & 4,75 & 0,5 \\
3 & 4,75 & 0,5 \\
4 & 4,75 & 0,5 \\
5 & 4,75 & 0,5 \\
6 & 5,00 & 0,0 \\
7 & 5,00 & 0,0 \\
8 & 5,00 & 0,0 \\
9 & 4,75 & 0,5 \\
10 & 4,75 & 0,5 \\
11 & 4,75 & 0,5 \\
12 & 4,75 & 0,5 \\
13 & 4,75 & 0,5 \\
14 & 4,75 & 0,5 \\
15 & 4,75 & 0,5 \\
16 & 4,75 & 0,5 \\
17 & 4,75 & 0,5 \\
Semua & 4,79 & - \\
pernyataan & & \\
\hline
\end{tabular}

\subsection{Hasil Pengembangan Sistem Informasi Manajemen Gim}

Gambar 8 memperlihatkan layar manajemen soal di SIMGEJA. Sebelum memasuki layar itu, pengguna harus memilih salah satu dari soal-soal di PJA. Setelah itu, layar tersebut akan ditampilkan agar pengguna dapat memodifikasi soal yang dipilih. Halhal yang dapat dimodifikasi adalah kedua angka yang hendak dijumlahkan dan gambar benda yang mewakili masing-masing angka. Gambar tersebut akan diambil dari sejumlah gambar yang kami sediakan di basis data SIMGEJA.

Secara keseluruhan, fitur manajemen soal di SIMGEJA tersebut cukup sederhana, dan 
kesederhanaan tersebut bertujuan untuk mengakomodasi para guru TK Lintang yang masih awam TIK dan belum yakin dapat menggunakan PJA dengan baik. Walau demikian, fitur-fitur SIMGEJA dapat kami perkaya di kemudian hari jika ada permintaan untuk itu dari para guru.

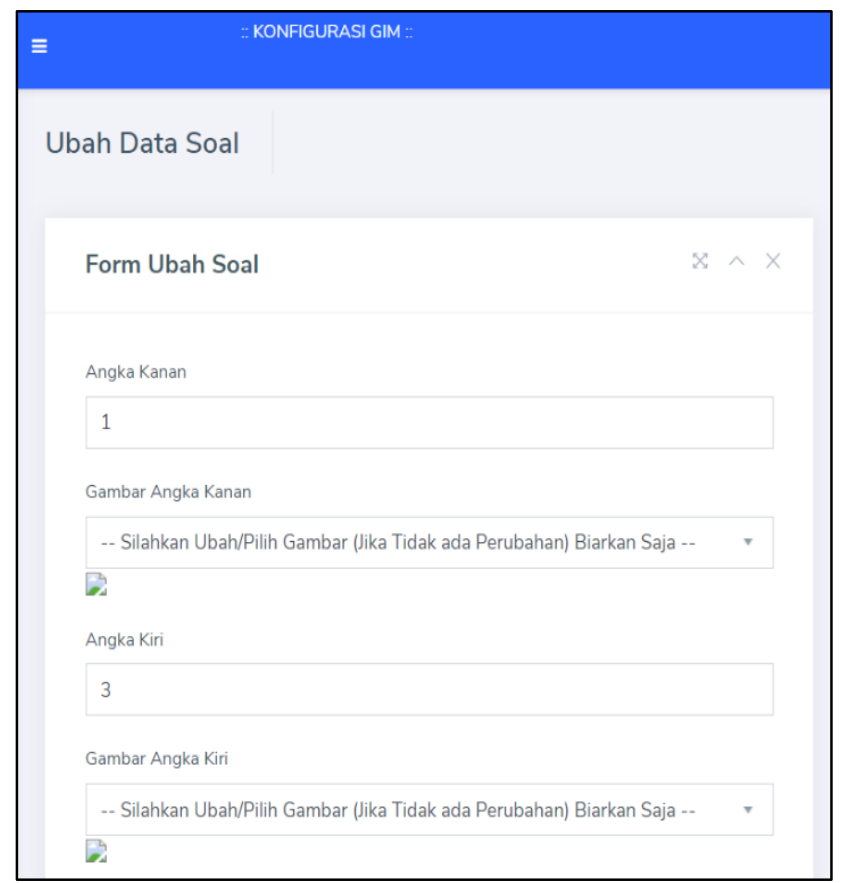

Gambar 8. Tampilan manajemen soal di SIMGEJA

\subsection{Hasil Finalisasi Gim}

Di akhir iterasi kedua, kami menghasilkan dua versi final PJA yang berbasis mobile dan desktop. Dengan GameMaker Studio 2, kami dapat mengubah PJA versi desktop menjadi versi mobile-nya dengan mudah dan cepat. Gambar 9 memperlihatkan versi mobile PJA yang dapat dimainkan di perangkat berbasis Android. Versi mobile akan digunakan para siswa selama pembelajaran di rumah, sementara versi desktop akan digunakan di TK Lintang.

Versi Android PJA dapat difungsikan sebaik versi desktop-nya. Walau demikian, versi tersebut belum diuji oleh para siswa dan orangtua. Kami berencana melakukan pengujian tersebut di kemudian hari.

\subsection{Ekstraksi Prinsip-Prinsip Penerapan Gim Edukasi}

Berdasarkan pengalaman dan hasil-hasil yang kami dapatkan, kami dapat mengekstrak sejumlah prinsip penerapan gim edukasi untuk prasekolah di masa normal baru:

1. Prioritaskan kemudahan penggunaan gim edukasinya, baik bagi guru, siswa, maupun orangtua siswa;

2. Gunakan alat pengembangan yang mendukung multiplatform untuk mengakomodasi berbagai konteks penggunaan gimnya di rumah maupun di lembaga prasekolahnya;

3. Sesuaikan gaya visual, permainan, dan narasi cerita gimnya agar menarik bagi siswa prasekolah;

4. Mudahkan integrasi gimnya ke dalam proses belajar-mengajar di lembaga prasekolahnya melalui fitur-fitur modifikasi soal dan semacamnya; dan

5. Sajikan jalan permainan dan cerita gimnya agar menarik dimainkan siswa bersama orangtuanya dalam rangka "waktu keluarga" atau "family time".

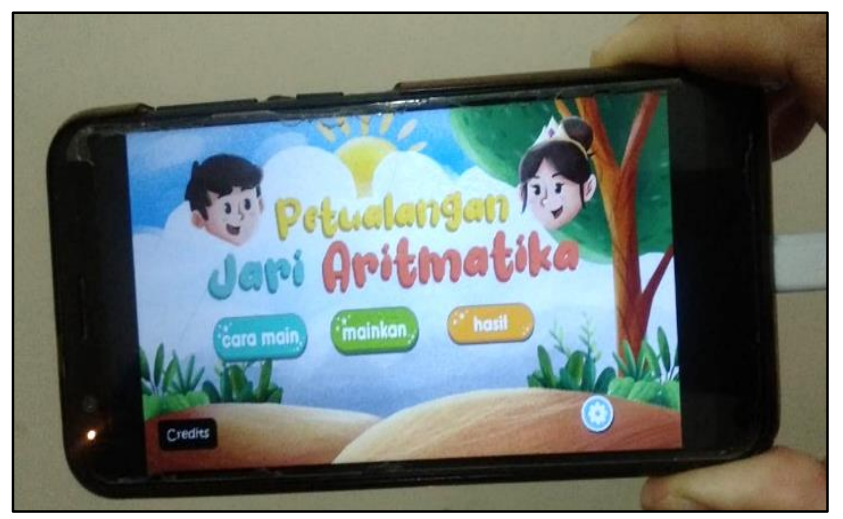

Gambar 9. Versi mobile PJA di smartphone ASUS Zenfone Max

\section{KesimpUlAN}

Kami telah meneliti penerapan gim edukasi untuk pendidikan normal baru prasekolah melalui pengembangan dan penerapan gim "Petualangan Jari Aritmatika" (PJA) di TK Lintang Surabaya. PJA berjenis novel visual dan digunakan untuk memfasilitasi pembelajaran metode Jari Aritmetika yang dibungkus animasi kartun bergaya gambaran tangan (hand-drawn) dan narasi cerita. Animasi tangan peraga Jari Aritmetika di PJA memfasilitasi pembelajaran metode tersebut secara visual, sehingga para siswa dapat menirukan dan mempraktekkan langsung. Kami mengembangkan PJA dalam dua iterasi dan menghasilkan dua versinya (mobile dan desktop) dan sistem informasi untuk memodifikasi soal-soal aritmetikanya. PJA telah diuji empat siswa yang didampingi orangtua masing-masing, menghasilkan nilai 4,79 dari maksimal 5 untuk efektivitasnya sebagai media hiburan dan edukasi. Berdasarkan proses pengembangan yang telah kami jalani, kami juga telah mengekstrak lima prinsip penerapan gim edukasi untuk pendidikan prasekolah normal baru, yang salah satunya adalah "mendukung waktu keluarga atau family time di antara siswa dan orangtuanya". 


\section{UCAPAN TERIMA KASIH}

Kami mengucapkan terima kasih kepada dua pihak:

1. TK Lintang, yang bersedia bekerja sama dengan kami di tengah berbagai hambatan yang disebabkan pandemi COVID-19;

2. Universitas Pembangunan Nasional "Veteran" Jawa Timur, yang telah mendanai kegiatan kami melalui hibah Penerapan Hasil Penelitian bagi Masyarakat (PIHAT).

\section{DAFTAR PUSTAKA}

[1] W. Van Lancker dan Z. Parolin, "COVID-19, school closures, and child poverty: a social crisis in the making", The Lancet Public Health, vol. 5, no. 5. hal. e243-e244, 2020.

[2] L. Zhou, S. Wu, M. Zhou, dan F. Li, "The Largest Online Education in the World Today: Taking China's Practical Exploration During The COVID-19 Epidemic Prevention and Control As an Example", SSRN Electronic Journal, Vol. 4, no. 2, Hal. 501 - 519,, 2020.

[3] J. Kim, "Learning and Teaching Online During Covid-19: Experiences of Student Teachers in an Early Childhood Education Practicum", International Journal of Early Childhood, vol. 52, no. 2, hal. 145-158, 2020.

[4] Z. Xie dan J. Yang, "Autonomous Learning of Elementary Students at Home During the COVID-19 Epidemic: A Case Study of the Second Elementary School in Daxie, Ningbo, Zhejiang Province", China, SSRN Electronic Journal, Vol 4, no. 2, hal. 535 - 541, 2020.

[5] W. Bao, "COVID-19 and online teaching in higher education: A case study of Peking University," Human Behavior and Emerging Technologies, vol. 2, no. 2, hal. 113-115, 2020.

[6] M. Nicola, "The socio-economic implications of the coronavirus pandemic (COVID-19) A review," International Journal of Surgery, vol. 78, hal. 185-193, 2020.

[7] J. Voogt, G. Knezek, R. Christensen, dan K.-W. Lai, "Developing an Understanding of the Impact of Digital Technologies on Teaching and Learning in an Ever-Changing Landscape", di Second Handbook of Information Technology in Primary and Secondary Education, Springer International Publishing, hal. 3-12, 2018.

[8] J. L. Plass, B. D. Homer, dan C. K. Kinzer, Foundations of Game-Based Learning, Educational Psychologist, vol. 50, no. 4, hal. 258283, 2015.

[9] S. S. Adkins, "The 2017-2022 Global Gamebased Learning Market," Serious Play Conference, hal. 1-20, 2017.

[10] R. L. Lamb, L. Annetta, J. Firestone, dan E.
Etopio, "A meta-analysis with examination of moderators of student cognition, affect, and learning outcomes while using serious educational games, serious games, and simulations", Computers in Human Behavior, vol. 80, hal. 158-167, 2018.

[11] J. N. Proulx, M. Romero, dan S. Arnab, "Learning Mechanics and Game Mechanics Under the Perspective of Self-Determination Theory to Foster Motivation in Digital Game Based Learning", Simulation and Gaming, vol. 48, no. 1, hal. 81-97, 2017.

[12] C. C. Chang, C. Liang, P. N. Chou, dan G. Y. Lin, "Is game-based learning better in flow experience and various types of cognitive load than non-game-based learning? Perspective from multimedia and media richness", Computers in Human Behavior, vol. 71, hal. 218227, 2017.

[13] P. W. Atmaja, F. Muttaqin, dan S. Sugiarto, "Facilitating educational contents of different subjects with context-agnostic educational game: A pilot case study", Register: Jurnal Ilmiah Teknologi Sistem Informasi, vol. 6, no. 1, hal. 5365, 2020.

[14] A. A. Syahidi, H. Tolle, A. A. Supianto, dan T. Hirashima, "TOLSYASUPI-EduMed: Development of Educational Media Using the Problem-Posing Learning Model for Basic Programming Subjects", Journal of Information Technology and Computer Science, vol. 4, no. 2, hal. 137-155, 2019.

[15] G. Kokkalia, A. Drigas, A. Economou, P. Roussos, dan S. Choli, "The use of serious games in preschool education", International Journal of Emerging Technologies in Learning, vol. 12, no. 11, hal. 15-27, 2017.

[16] C. Zanchi, A. L. Presser, dan P. Vahey, "Next generation preschool math demo: Tablet games for preschool classrooms", ACM International Conference Proceeding Series, hal. 527-530, 2013.

[17] G. P. Papanastasiou, A. S. Drigas, dan C. Skianis, "Serious games in preschool and primary education: Benefits and impacts on curriculum course syllabus", International Journal of Emerging Technologies in Learning, vol. 12, no. 1, hal. 44-56, 2017.

[18] L. K. Thai dan M. H. Mohd Yasin, "Magic Finger Teaching Method in Learning Multiplication Facts among Deaf Students", Journal of Education and Learning, vol. 5, no. 3, hal. 40-50, 2016.

[19] A. Martono, J. Junaidi, dan D. Yuliana, "Imulation game based on jarimagic method to calculate more quickly for elementary students", CSRID, vol. 3, no. 3, hal. 149-164, 2011.

[20] F. Ahmadi dan W. Weijun, "The Effect of ' jarimatika' Multimedia in Counting Ability of 
Children," Information and Knowledge Management, vol. 4, no. 6, hal. 40-47, 2014.

[21] E. Naul dan M. Liu, "Why Story Matters: A Review of Narrative in Serious Games", Journal of Educational Computing Research, vol. 58, no. 3, hal. 687-707, 2020.

[22] H. Ç. Sarica dan Y. K. Usluel, "The effect of digital storytelling on visual memory and writing skills," Computers and Education, vol. 94, hal. 298-309, 2016.

[23] C. Symborski, M. Barton, M. M. Quinn, J. H. Korris, K. S. Kassam, dan C. K. Morewedge, "The Design and Development of Serious Games Using Iterative Evaluation", Games and Culture, vol. 12, no. 3, hal. 252-268, 2017.

[24] R. Scherer, F. Siddiq, dan J. Tondeur, "The technology acceptance model (TAM): A metaanalytic structural equation modeling approach to explaining teachers' adoption of digital technology in education", Computers and Education, vol. 128, hal. 13-35, 2019.

[25] J. Camingue, E. F. Melcer, dan E. Carstensdottir, "A (Visual) Novel Route to Learning: A Taxonomy of Teaching Strategies in Visual Novels", International Conference on the Foundations of Digital Games, 2020.

[26] M. H. Phan, J. R. Keebler, dan B. S. Chaparro, "The Development and Validation of the Game User Experience Satisfaction Scale (GUESS)", Human Factors, vol. 58, no. 8, hal. 1217-1247, 2016.

[27] F. L. Fu, R. C. Su, dan S. C. Yu, "EGameFlow: A scale to measure learners' enjoyment of elearning games", Computers and Education, vol. 52, no. 1, hal. 101-112, 2009. 